\title{
A influência dos pigmentos amarelo- laranja de vários alimentos na coloração da gema de ôvo de galinha *
}

\author{
E. A. GRANER \\ . Escola Superior de Agricultura "Luiz de Queiroz" \\ Universidade de São Paulo
}

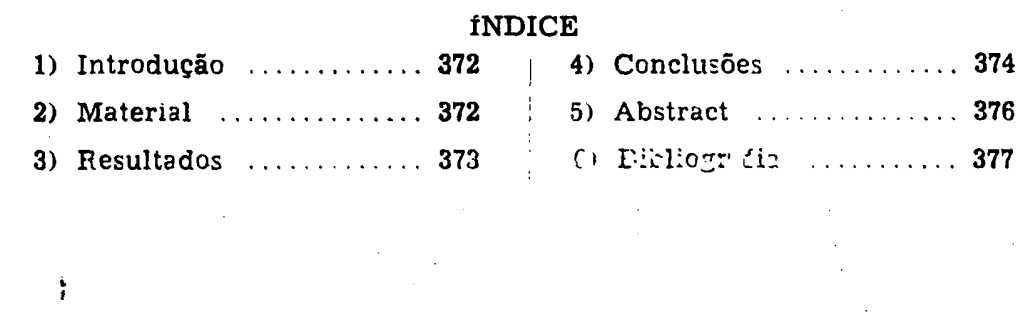

* Trabalho da Seção de Avicultura e Cunicultura 


\section{1) INTRODUÇÅO}

Em trabalho anterior (4) tivemos a ocasiáo de mostrar a influência dos pigmentos amarelo-laranja dos grãos de milho na coloração da gema de ôvo de galinha. Dois típos de milho, de importância econômica no Estado, foram então utilizados : o milho "Cateto", com grãos laranja-forte e o milho "Armour" com grãos amarelo-laranja. A intensidade de coloração da gema foi proporcional à quantidade de xantofila zeaxantina fornecida pelos grãos e a qual foi pràticamente em dôbro no milho "Cateto" em relação àquela do milho "Armour".

A influência dos pigmentos do almeirăo, como alimento verde, foi também examinada e observámos a possibilidade de variação conforme a fonte de pignientos introduzida na ração. Neste trabalho vamos relatar a influência de vários alimentos na coloração da gema, tomando como base de comparação aquela obtida com milho de gráos coloridos.

\section{2) MATERIAL}

A presente experiência foi feita na mesma base da anteriormente realizada (4). Dez galinhas devidamente aneladas foram submetidas a uma ração composta de $70 \%$ de milho (branco ou colorido) e $30 \%$ de outros ingredientes, pràticamente isentas de pigmentos que pudessem influir na coloração da gema. A essa ração básica foram adicionados os diversos alimentos cuja influência na coloração da gema se desejava conhecer. A ração assim combinada era dada às galinhas durante cêrca de 10 dias e entre cada tipo de alimentação as galinhas permaneciam por um período de cêrca de uma semana recebendo sòmente ração sem qualquer fonte de pigmentos. Os ovos depois de coletados foram quebrados e a coloração das gemas comparada à tábua de MAERZ e PAUL (9). Para facilitar, as diversas tonalidades obtidas foram reunidas nas mesmas quatro classes da experiência anterior, chamadas amarelo-claro, amarelo, laranja e laranja-forte. Os resultados de tôdas as galinhas, para cada alimcnto empregado, foram reunidos e a média qualitativa representada por meio de colunas no gráfico incluso. Não fizemos asșị uma repreșentação 
por galinha, como na outra vez, pelo fato de ter esta experiência durado muito mais tempo e assim, algumas galinhas terem sustado a postura em algumas ocasióes.

\section{3) RESULTADOS}

O gráfico incluso mostra bem claramente o efeito dos diferentes alimentos na coloração da gema de ôvo de galinha. Os quatro tipos de coloração estão representados na vertical e na horizontal as diversas combinaçōes de alimento empregadas, numeradas de 1 a 18 e a saber respectivamente :

1. : Ração com milho "Cateto" (laranja-forte).

2. : Ração com milho "Armour" (amarelo-laranja).

3. : Ração com milho "Cristal" (branco).

4. : Ração com milho "Cateto" + 20 grs. de almeirão por galinha e por dia.

\section{Por galinha e por dia}

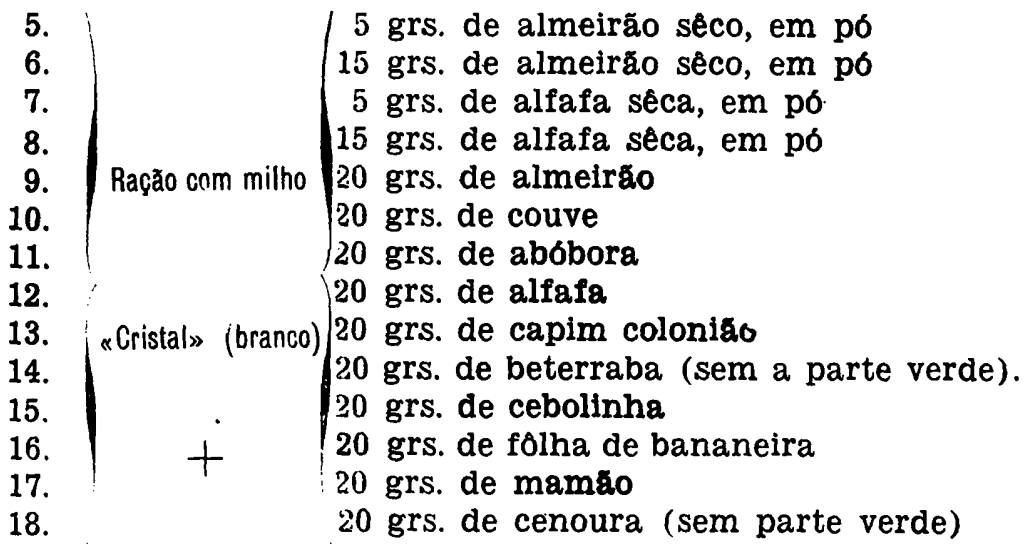

Pudemos constatar que a maior coloração da gema fol aquela obtida com o emprégo combin?do de milho "Cateto" C fôlhas de almeirão (N.0 4). Os ovos das galinhas quando receberam esta combinação apresentaram as suas gemas com uma coloraçáo laranja bastante forte. A falta do almeirăo, numa raçáo contendo 70\% de milho "Cateto" não prejudicou muito essa intensidade de coloração (N.0 1). As gemas apresentaram ainda uma coloração laranja forte, se bem que năo tão 
Intensa como quando o almeirão era empregado juntamente com o milho laranja. Logo a seguir, de acórdo com a intensidade da coloraçáo da gema, vem o almeirăo (N.0 6) e a alfafa (N.0 8), sécos, em pó, dados numa base de 15 grs. por gaI'nha e o almeiråo (N.० 9) e alfafa (N.0 12), verdes, dados numa base de 20 grs. por galinha. Estas quantidades de almeirão e alfafa, combinadas com a ração contendo milho branco, foram capazes de dar à gema uma coloração alaranjada, se bem que menos intensa do que aquela quando o milho "Cateto" foi utilizado na ração. Três outros alimentos, couve (N.0 10), cepolinha (N.O 15) e fólha de bananeira (N.0 16), empregados na quantidade de 20 grs. por galinha produziram uma coloração da gema também alaranjada, bem satisfatória, mas não tão Intensa como nos casos anteriores. Os demais alimentos empregados já não determinaram coloração laranja à gema. O milho "Armour", amarelo laranja (N.0 2) e a raçåo com milho branco combinada com sòmente 5 grs. de almeirăo (N.0 5) ou alfafa (N.0 7) em pó, por galinha, bem como combinada com 20 grs. por galinha de capim coloniăo (N.0 13) e de mamão (N.0 17), foram capazes de imprimir à gema uma coloração apenas amarela, porém ainda bastante satisfatória. O emprêgo de 20 grs. de abóbora por galinha (N.0 11) em combinação com a ração contendo milho branco, foi também suficiente para dar à gema uma coloração amarela, não tão forte como nos outros casos. A beterraba (N. ${ }^{\circ}$ 14) e a cenoura (N.0 18) sem a parte verde, fornecidas na mesma base, em combinação com a ração de milho branco, produziram apenas uma coloração amarelo-clara, pouco satisfatória. Finalmente, o emprêgo duma ração com milho "Cristal" branco (N.o 3) sem combinação com outros alimentos, deixou as gemas com coloração amarela, muito clara. muito longe de apresentar a tonalidade desejada pelo consumidor brasileiro.

\section{4) CONCLUSOES}

A coloração intensa da gema do óvo de galinha, como salientámos em outro trabalho, é um requisito muito apreciado pelo consumidor brasileiro, embora em outros paises possa constituir um defeito. Essa coloraçăo é diretamente influenciada pela alimentaçăo utilizada $e$ isto, do ponto de vista comercial, é bastante importante, pois pode-se dar a ela a tonalidade requerida pelo mercado. 


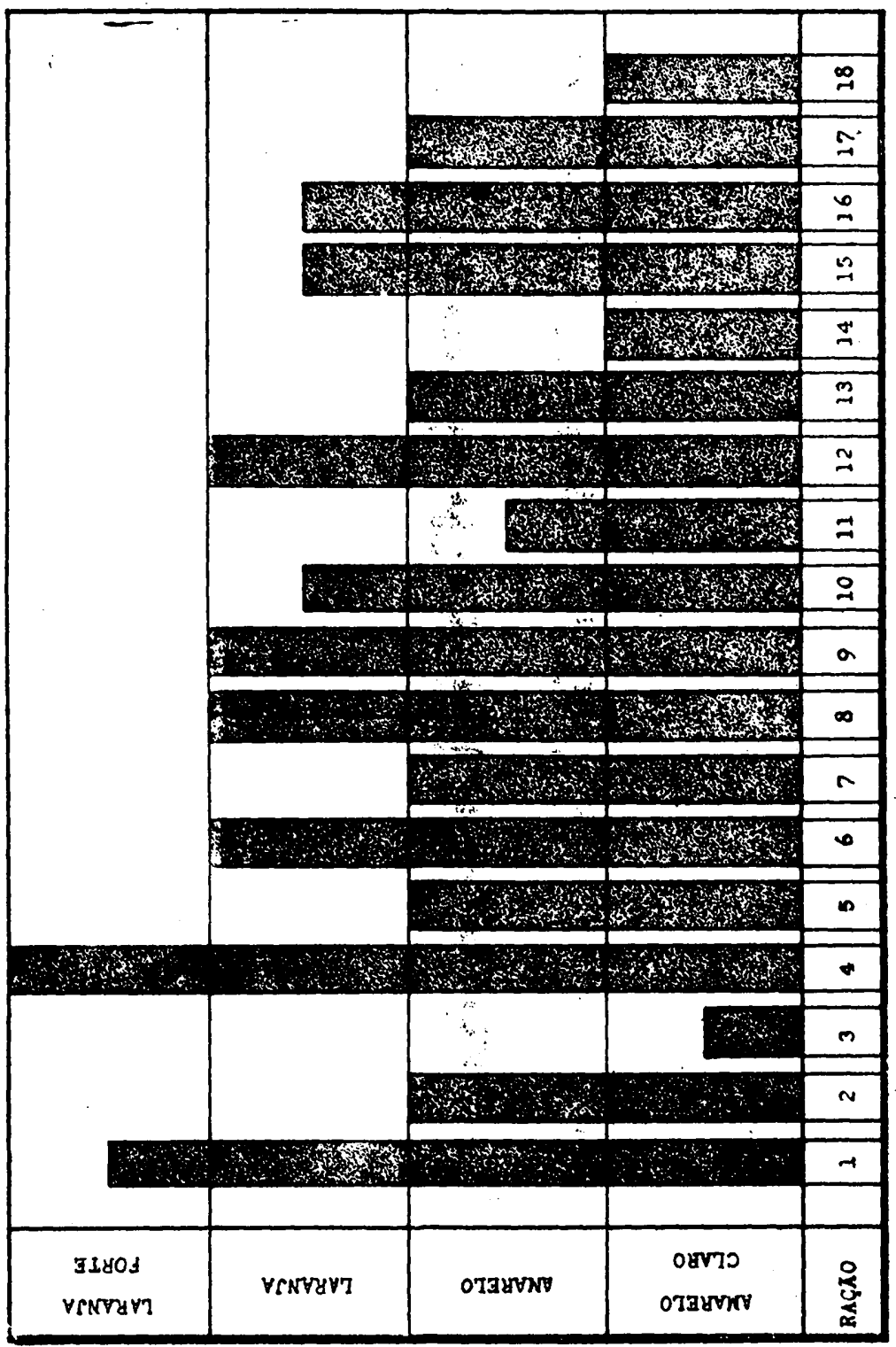


Dos pigmentos do grupo carotenóides, săo as xantofilas zeaxantina e luteina as principais encontradas na gema. Pigmentos como caroteno, criptoxantina, neoxantina e outros podem ser também encontrados na gema, porém em quantidades muito pequenas, porque são transformados no metabolismo. Assim, todo alimento rico das xantofilas zeaxantina e luteina é capaz de produzir ovos com gema bastante colorida, como acontece quando o milho amarelo utilizado, pois seus grãos contém grande quantidade de zeaxantina, sendo que o milho "Cateto" possui cêrca do dóbro da quantidade encontrada no mitho "Armour" (4). A potencialidade de vários alimentos de imprimir coloração à gema do ôvo de galinha em comparação àquela do milho foi estudada, tendo-se verificado que os resultados obtidos não contrariam aquelcs encontrados por outros autores. De forma geral, o verde é capaz de produzir uma coloração boa na gema. Assim, resultados satisfatórios foram obtidos com os seguintes alimentos que deram gemas de tonalidade alaranjada: almeirão, alfafa, couve, cebolinha e bananeira. Também o almeirão e alfafa, secos e em pó, em quantidade mais ou menos grande (15 grs. por galinha) produzem gemas com coloração alaranjada. Cóloração amarela, ainda bastante satisfatória pode ser obtida com capim coloniäo e mamão ou então almeirão e alfafa, secos e em pó, em quantidade pequena ( 5 grs. por galinha). A beterraba e a cenoura, sem a parte verde, bem como a abóbora, mostraram-se insuficientes para dar uma coloração bóa, sendo portanto pobres em pigmentos do grupo das xantofilas. Os alimentos como abóbora, cenoura, mamão e outros, embora muito coloridos, são ricos de pigmentos que não passam diretamente à gema, entre os quais se encontram aquêles que são transformados em vitamina A, incolor. Nossas observações permitem cor.cluir a) que o milho de grãos laranja combinado com alimento verde, produz gemas bastante coloridas; b) que na falta de alimento verde, o milho de grãos coloridos amarelo-laranja ou laranja dão uma coloração satisfatória às gemas e c) que na falta de milho de grãos coloridos, os seguintes alimentos podem ser utiíziados com resultado satisfatório : em primeiro lugar, almeirão, alfafa, couve, cebolinha e bananeira e em segundo lugar, capim colonião e mamão.

\section{5) ABSTRACT}

The effect of different feeds in comparison with that of malze grains on the egg yolk color was observed. It was found 
that deep orange and yellow orange maize give satisfactory coloration to the yolk, respectively orange and yellow. Themost intense color was observed when green feed was used in combination with deep orange maize. Green feeds as chicrry, alfafa, cabbage, welsh onion and banana leaves and alfafa or chicory meal proved to be good in giving orange color to the yolk. Yellow yolk was obtained when Guinéa grass or carica fruit were used in the ration. Carrot and beet without leaves did not give satisfactory color to the egg yolk. The observations with other feeds are being continued.

\section{6) BIBLIOGRAFIA}

1) ALBRIGHT, W. P. and R. B. THOMPSON (1935) Variations of yolk color and characteristics produced by feeding and environment. Poultry Science 14:373-375.

2) GISH, C. L., L. F. PAYNE and W. J. PETERSON (1940) The effect of grass silage on color of egg yolk. Poultry Science 19:154-156.

3) GRANER, E. A. (1946)) A importância do milho amarelo na alimentação dos animais. Revista de Agricultura 21:5-7.

4) GRANER, E. A. (1946) A influência dos pigmentos amarelo-laranja da semente de milho na coloração da gema de ôvo de galinha. Anais da Escola Superior de Agricultura "Luiz de Queiroz" 3:425-436.

5) HEIMAN, V. and L. A. WILHELM (1937) The transmission of xantophylls in feeds to the yolk of hen's egg. Poultry Science 16:400-403.

6) HENDERSON, E. W. and H. L. WILKE (1933) Effect of ration on yolk color. Poultry Science 12:266-273.

7) HUGHES, J. S. and L. F. PAYNE (1937) The relation of carotenoid pigments of feed to the carotenoid of egg yolk. Poultry Science 16:135-138.

8) JULL, M. A. (1938) Poultry Husbandry. Mc-Graw-Hill Book Company Inc., New York.

9) MAERZ, A. and. M. R. PAUL (1930) Dictionary of color. McGraw-Hill Book Company Inc., New York. 
10) MATTIKOW, M. (1932) A critical review of literature on the coloring matter in egg yolk. Poultry Science 11:83-93.

11) OLSEN, M. W. (1942) Acorns one cause of olive-colored yolks. Poultry Science $21: 497: 499$.

12) PARKER, S. L, S. S. GOSSMAN and W. A. LIPPINCOTT. I - Introductory note on variations in yolk color. Poultry Science 5:131-145.

13) PAYNE, L. F. (1925) The cause of olive-colored egg yolk. Poultry Science 4:102:108.

14.) SWENSEN, A. D., E. A. FIEGER and C. W. UPP (1942) The nature of egg yolk discoloration produced by cotton-seed meal. Poultry Science 21:374-378.

i5) TITUS, H. W., J. C. FRITZ and W. R. KAUFFMANN (1938) Some observations on egg-yolk color. Poultry Science 17: 38-45.

I'; W. LFELM, L. A. and V. HEIMAN (1937) The effect on yolk culor cf var.ous ingredients in poultry feeds. Poultry Science $10: 416-418$. 